\title{
Biotransformation and nitroglycerin-induced effects on antioxidative defense system in rat erythrocytes and reticulocytes
}

\author{
Snežana D. Marković ${ }^{1}$, Nataša Z. Đorđević ${ }^{2}$, Milena G. Curčić ${ }^{1}$, Andraš Š. Štajn ${ }^{1}$ \\ and Mihajlo B. Spasićc \\ ${ }^{1}$ Department for Biology and Ecology, Faculty of Science, University of Kragujevac, Radoja Domanovića 12, 34000 Kragujevac, \\ Serbia \\ ${ }^{2}$ Department of Biomedical Science, State University of Novi Pazar, Vuka Karadžića bb, 36300 Novi Pazar, Serbia \\ ${ }^{3}$ Department of Physiology, Institute for Biological Research "Siniša Stanković", Bulevar despota Stefana 142, 11060 \\ Belgrade, Serbia
}

\begin{abstract}
The effects of nitroglycerin (glyceryl trinitrate - GTN) are mediated by liberated nitric oxide (NO) and formed reactive nitrogen species, which induces oxidative stress during biotransformation in red blood cells (RBCs). The aim of this study was to evaluate effects of GTN on antioxidative defense system (AOS) in rat erythrocytes (without) and reticulocytes (with functional mitochondria). Rat erythrocyte and reticulocyte-rich $\mathrm{RBC}$ suspensions were aerobically incubated $\left(2 \mathrm{~h}, 37^{\circ} \mathrm{C}\right)$ without (control) or in the presence of different concentrations of GTN $(0.1-1.5 \mathrm{mM})$. After incubation, concentrations of non-enzymatic components of AOS, activities of antioxidative enzymes and oxidative pentose phosphate (OPP) pathway activity were followed in RBC suspensions. In rat reticulocytes, GTN decreased the activity of mitochondrial MnSOD and increased the activity of CuZnSOD. In rat RBCs, GTN induced increase of Vit E concentration (at high doses), but decreased glutathione content and activities of all glutathione-dependent antioxidative enzymes; the OPP pathway activity significantly increased. GTN biotransformation and induction of oxidative stress were followed by general disbalance of antioxidative capacities in both kinds of RBCs. We suggest that oxidative stress, MnSOD inhibition and depletion of glutathione pool in response to GTN treatment lead to decreased bioavailability of NO after GTN biotransformation in rat reticulocytes.
\end{abstract}

Key words: Antioxidative defense system - MnSOD - Nitric oxide - Nitroglycerin - Red blood cells

\section{Introduction}

The main role of erythrocytes is the transport of hemoglobin $(\mathrm{Hb})$ which supplies oxygen to all tissues in the body. The hem iron is carried in a ferrous state (Fe(II)), a reduced form that can be oxidized to the ferricFe(III) form (methemoglobin-MetHb), analogous to the cytochrome system (Umbreit 2007). The auto-oxidation of oxyhemoglobin to MetHb generating superoxide anion radical $\left(\mathrm{O}_{2}{ }^{--}\right)$represents the main source of free radicals in the erythrocytes (Nikolic-Kokic et

Correspondence to: Snežana D. Marković, Department for Biology and Ecology, Faculty of Science, University of Kragujevac, Radoja Domanovića 12, 34000 Kragujevac, P.O. Box 60, Serbia E-mail: smarkovic@kg.ac.rs al. 2010). When $\mathrm{Hb}\left(\mathrm{Hb}(\mathrm{Fe}(\mathrm{II})) \mathrm{O}_{2}\right)$ is autooxidized to MetHb ( $\mathrm{Hb}(\mathrm{Fe}(\mathrm{III}))$, MetHb is recycled back to $\mathrm{Hb}(\mathrm{Fe}(\mathrm{II})$, so that in the steady state the amount of intracellular MetHb is $<1 \%$. Hence, $\mathrm{Hb}$ also regulates vascular tone and inflammation via redox coupled with MetHb (Umbreit 2007). MetHb is reduced by the NADH-cytochrome b5-metHb reductase, and also by several alternative pathways such as direct reduction by intracellular ascorbate and glutathione (Umbreit 2007). Red blood cells (RBCs, including mature erythrocytes and immature reticulocytes) are also the main site of nitric oxide (NO) metabolism. Hemoglobin in deoxy-form acts as nitrite reductase, yielding $\mathrm{NO}$ and $\mathrm{MetHb}$ (Cosby et al. 2003; Huang et al. 2005).

Reticulocytes, as premature erythrocytes, do not possess a full range of metabolic pathways compared to proliferat- 
ing cells, but they are still equipped with a set of metabolic pathways, due to the presence of mitochondria and ribosome (Rapoport 1986). In experimental conditions, reticulocytosis is induced by bleeding or by phenylhydrazine-hydrochloride (PhCl) treatment (Rapoport 1986). In comparative studies, reticulocytes and erythrocytes were used as simple model systems to differentiate the mitochondria-dependent metabolic processes in these cells (Marković et al. 2006, 2007, 2011). In reticulocytes, primary consumers of oxygen and primary ATP generators are mitochondria which are a permanent source of reactive oxygen species (ROS). Oxidative stress as a consequence of increased production of ROS and reactive nitrogen species (RNS) and depletion in antioxidant protection (antioxidative defense system - AOS) induces dysfunction and death of cells (Dröge 2002; Kuka et al. 2013).

Exogenous donation of NO may be useful in the treatment of some disease states. The action of nitroglycerin (glyceryl trinitrate - GTN) is mediated by the liberation of NO after enzymatic biotransformation by mitochondrial aldehyde dehydrogenase - ALDH-2 (Chen et al. 2002; Sydow et al. 2004). Also, direct interaction of GTN with low-molecularweight thiols may produce vasodilator S-nitrosothiols in vivo (Boesgaard 1995), as well as, biotransformation of GTN by erythrocytes is due to the interaction with $\mathrm{Hb}$ (Bennett et al. 1985). Previously, we showed that GTN biotransformation was different in erythrocytes and reticulocytes due to the presence of mitochondria in the latter (Marković et al. 2006). In rat erythrocytes, GTN biotransformation was primarily connected with $\mathrm{Hb}$, while in reticulocytes, two pathways of GTN biotransformation existed: one generating mitochondria-dependent RNS and the other connected with $\mathrm{Hb}$ as in erythrocytes. Metabolic pathways of endogenous synthesis and degradation of NO are closely connected with metabolic pathways of redox and antioxidative metabolism, especially with glutathione system (Hogg 2002). Literature data showed that mitochondrial Mn superoxide dismutase (MnSOD) may have been included in NO metabolism (Niketić et al. 1999; Filipović et al. 2007). Sydow et al. (2004) and Daiber et al. (2009) suggest that GTN-induced increase in ROS production contributes to inhibition of ALDH-2 and consequently mediates nitrate tolerance.

In this study, we have examined the effects of GTN on antioxidative defence system and biotransformation of GTN in rat erythrocytes and reticulocytes, considering the role of mitochondria in the latter.

\section{Materials and Methods}

\section{Reagents}

GTN (a Nirmin ampule) was obtained from Zorka (Šabac, Serbia). Phenylhydrazine-hydrochloride $(\mathrm{PhCl})$, Hepes, 5,5-dithio-bis-6,2-nitrobenzoic acid (DTNB), glutathione reductase (GR), GSH, GSSG, N-ethylmaleimide (NEM), pyrogallol, nicotinamide adenine dinucleotice phosphate (NADPH), t-butyl-hydroperoxide, 1-chloro-2,4-dinitrobenzene (CDNB), $\left[1-{ }^{14} \mathrm{C}\right]$-glucose and $\left[6-{ }^{14} \mathrm{C}\right]$-glucose, phenetylamine were purchased from Sigma (St. Louis, MO). All other chemicals used were of the highest purity commercially available.

\section{Animals}

Erythrocyte and reticulocyte-rich RBC suspensions of Wistar albino, rats, (body weight 250-350 g) were used in this study. The animals were kept at $21 \pm 1^{\circ} \mathrm{C}$ and exposed to a $12 \mathrm{~h}$ light $/ 12 \mathrm{~h}$ dark cycle. All rats were housed in individual cages and given standard diet and water ad libitum. Reticulocytosis was induced by $\mathrm{PhCl}$ treatment $(35 \mathrm{mg} / \mathrm{kg}$ body mass during three days) (Kostić et al. 1990). Rats were divided in the two experimental groups: untreated (for erythrocyte-rich $\mathrm{RBC}$ suspension collection) and $\mathrm{PhCl}$ treated rats (for reticulocyte-rich RBC suspension collection). During experiments with animals our in-house ethical committee-approved protocol was followed.

\section{Experimental protocol}

Untreated and $\mathrm{PhCl}$-treated (after 7-8 days of the first $\mathrm{PhCl}$ injection) rats were anaesthetized using ether, and blood was taken by exsanguinations. Blood was pooled from two or three animals in each experimental group and each individual experiment. In the blood obtained from $\mathrm{PhCl}-$ treated rats the reticulocytes amounted $86.57 \pm 1.28 \%$ of total RBCs. Three times washed (in $0.9 \% \mathrm{NaCl}$ ) erythrocytes (obtained from untreated rats), as well as reticulocyte-rich $\mathrm{RBC}$ suspensions (obtained from $\mathrm{PhCl}$-treated rats) were resuspended in an incubation buffer containing $50 \mathrm{mM}$ Hepes, $100 \mathrm{mM} \mathrm{NaCl}, 1 \mathrm{mM} \mathrm{MgCl} 2,1 \mathrm{mM} \mathrm{NaH}{ }_{2} \mathrm{PO}_{4}$, $5 \mathrm{mM}$ glucose and $2 \mathrm{mM} \mathrm{CaCl}_{2}, \mathrm{pH} 7.4$ at $37^{\circ} \mathrm{C}$ (Kostić et al. 1990). Cell suspensions contain about $20 \%$ of RBCs (exact final hematocrits were measured for each cell suspensions during each individual experiment; these values used for calculation of amount of RBCs and expressed in ml cells). Cell suspensions which were obtained in this way were aerobically incubated for 2 hours, without (control), or in the presence of different concentrations of GTN $(0.1,0.25$, $0.5,1.0$ and $1.5 \mathrm{mM})$. GTN was added at the beginning of the incubation (at $0 \mathrm{~min}$ ). Extractions were performed after incubations. Our previous results showed that reticulocytes had higher MetHb level compared with untreated erythrocytes, while GTN treatment induced increase of MetHb in both cells (Marković et al. 2006). Concentration of superoxide anion radical decreased in rat RBCs in the presence of GTN (Marković et al. 2006). 


\section{Analytical methods}

\section{Determination of non-enzymatic components of AOS}

Non-enzymatic components of AOS were determined by using spectrophotometric techniques. After saponification and esterification of samples, vitamin E (Vit E) level was determined according to Desai (1984). Vitamin C (Vit C) was determined according to Day et al. (1979). Levels of reduced glutathione (GSH) were determined on the basis of GSH oxidation with 5,5-dithio-bis-6,2-nitrobenzoic acid (Beutler 1975a). The concentrations of oxidized glutathione (GSSG) were determined enzymatically by glutathione reductase, after inhibition of GSH oxidation by $\mathrm{N}$-ethylmaleimide (Beutler 1975b). Concentration of followed parameters were expressed in $\mu \mathrm{g}$ (for Vit E), $\mu \mathrm{mol}$ (for Vit C and GSH) and $\mathrm{nmol}$ (for GSSG) per ml cells, which calculated on the bases of exact hematocrit value measured for cell suspensions before incubation.

\section{Evaluation of AOS enzymes activities}

Antioxidative enzyme activities were determined in lysates of erythrocyte and reticulocyte-rich RBCs suspensions.

Superoxide dismutase (SOD) activity was determined after extraction using following protocol: to remove the $\mathrm{Hb}$, $1.0 \mathrm{ml}$ of an ethanol/chloroform $(1: 1, \mathrm{v} / \mathrm{v})$ mixture was added to an aliquot $(0.5 \mathrm{ml})$ of the lysate cooled on ice. This mixture was stirred constantly for $15 \mathrm{~min}$ before being diluted with $0.5 \mathrm{ml}$ of distilled water. After centrifugation for $10 \mathrm{~min}$ at $5000 \mathrm{rpm}$, the pale yellow supernatant was separated from the protein precipitate and was used to assay SOD enzyme activity. Owing to its ability to inhibit the auto-oxidation of pyrogallol, SOD activity was determined according to the method of Marklund and Marklund (1974). MnSOD activity was determined as SOD activity remaining after 15 minutes of reticulocyte-rich lysates incubation with $8 \mathrm{mM}$ $\mathrm{KCN}$, an inhibitor of CuZn containig SOD (CuZnSOD), at room temperature.

Catalase (CAT) activity was measured by the method of Beutler (1982). The method is based on the rate of $\mathrm{H}_{2} \mathrm{O}_{2}$ degradation by the action of CAT contained in the examined samples and followed spectrophotometrically at $230 \mathrm{~nm}$ in $1 \mathrm{M}$ Tris- $\mathrm{HCl}$ solution, containing $5 \mathrm{mM}$ EDTA, pH 8.0.

Glutathione peroxidase (GSH-Px) activity was assayed following the oxidation of nicotinamide adenine dinucleotice phosphate (NADPH) with t-butyl-hydroperoxide as a substrate (Maral et al. 1977). The activity of glutathione reductase was determined using the method of Glatzle et al. (1974). The method is based on the capacity of GR to catalyze the reduction of GSSG to GSH using NADPH as substrate. Glutathione-S-transferase (GST) activity towards 1-chloro- 2,4-dinitrobenzene (CDNB) as a substrate was measured according to the method of Habig et al. (1974).

The activities of SOD, CAT, GSH-Px, GR and GST were expressed in $\mathrm{U} / \mathrm{ml}$ cells (units of activities per $\mathrm{ml}$ cells, which calculated on the bases of exact hematocrit value).

The evaluation of oxidative pentose phosphate (OPP) pathway activity

For estimation of OPP pathway ${ }^{14} \mathrm{CO}_{2}$ formation was measured by Warburg technique. The incubation of erythrocytes with $\left[1-{ }^{14} \mathrm{C}\right]$-glucose and determination of $\left[1-{ }^{14} \mathrm{CO}_{2}\right]$, released during the conversion of glucose-6-phosphate into pentose phosphates, represent the direct measure of OPP pathway activity, since in mature RBCs (erythrocytes) it is the only site for metabolic production of $\mathrm{CO}_{2}$ (Rapoport 1986). However, for estimation of OPP pathway in reticulocytes, the ratio between the radioactivities of $\mathrm{CO}_{2}$ derived from $\left[1-{ }^{14} \mathrm{C}\right]$-glucose and $\left[6^{-14} \mathrm{C}\right]$-glucose should be used. In these cells which possess mitochondria and oxidative phosphorylation, $\left[6-{ }^{14} \mathrm{C}\right]$-glucose must be employed since ${ }^{14} \mathrm{CO}_{2}$ is mainly formed in tricarboxilic cycle. The OPP pathway activity was determined according to the method described by Yunis and Yasmineh (1969). Cell suspensions without (control) or with GTN $(01,1,0.25,0.5$ and $1 \mathrm{mM})$ were aerobically incubated at $37^{\circ} \mathrm{C}$ for 60 minutes in the presence of either $\left[1-{ }^{14} \mathrm{C}\right]$-glucose (erythrocytes), or $\left[1-{ }^{14} \mathrm{C}\right]$-glucose and $\left[6^{-14} \mathrm{C}\right]$-glucose (reticulocyte-rich RBC suspensions). After addition of labelled glucose to the cell suspensions, the specific radioactivity of glucose was usually $2500 \mathrm{cpm} / \mathrm{nmol}$. All incubations were performed in duplicate. Phenetylamine $(0.2 \mathrm{ml})$ was added as $\mathrm{CO}_{2}$ absorbent. The incubations were terminated by adding 0.5 vol. of cold $20 \%$ trichloracetic acid, followed by 30 minutes of shaking for the complete absorption of released ${ }^{14} \mathrm{CO}_{2}$. The radioactivity of the formed $\mathrm{CO}_{2}$ was measured in a toluene scintillator (Rack Beta Spectral, LKB Wallac). Glucose flux via OPP pathway was calculated and expressed in nmol glucose $/ \mathrm{ml}$ cells $/ \mathrm{h}$. In order to obtain the value for "pure", 100\% reticulocyte suspensions, the following equation was used: OPP $\mathrm{rtcs}$ ( $\mathrm{nmol}$ glucose $/ \mathrm{h} / \mathrm{ml}$ rtcs $)=[\mathrm{OPP}$ cells $-(\mathrm{OPP}$ ercs $\times \% \operatorname{ercs} / 100)] / \% \mathrm{rtcs} / 100$ (ercs, erythrocytes; rtcs, reticulocytes).

\section{Statistical analysis}

All values are expressed as mean \pm SEM. Statistical evaluation was calculated by Paired Sample T-Test and One-Way ANOVA, LSD Posthoc test (SPSS for Windows, ver. 17, 2008, Chicago, IL). For all comparisons, $p<0.05$ was considered significant. The magnitude of correlation between variables was done using a SPSS (Chicago, IL) statistical software package (SPSS for Windows, ver. 17, 2008). Results were given from five independent experiments. 


\section{Results}

The effects of GTN on concentrations of non-enzymatic components of $A O S$ in rat $R B C s$

Aerobic in vitro incubation of erythrocyte and reticulocyterich RBCs in the presence of GTN caused changes in the levels of antioxidative non-enzymatic components. According to the data presented in Tab. 1, GTN induced decrease of Vit C level (there is evident decreasing tendency without significant changes, except in $0.25 \mathrm{mM}$ GTN in erythrocytes; in reticulocytes high doses of GTN induces Vit C decrease). GTN significantly (in high doses) and dose-dependently (Tab. 3) increased Vit E level in both kinds of cells. The changes in antioxidative vitamin contents were higher in erythrocytes than in reticulocytes after GTN treatment.

After a 2-hour incubation of rat reticulocytes with GTN, the GSH content decreased significantly $(p>0.05)$ and dosedependently, while GSSG level did not changed (Tabs. 2, 3). In erythrocytes, only high doses of GTN induced depletion of complete glutathione pool (GSH and GSSG) (Tabs. 2, 3), indicating possible impairment of overall glutathione synthesis. These changes did not disturb the GSSG/2GSH ratio (Tab. 2). All data indicate that water soluble antioxidants
(Vit $\mathrm{C}$ and GSH) were included in antioxidative defence of RBCs.

The effects of GTN on antioxidative enzymes activities in rat RBCs

Antioxidative enzymes are also a very important part of AOS which specifically eliminates ROS. One of them is $\mathrm{SOD}$, which catalyses dismutation of $\mathrm{O}_{2}{ }^{\bullet-}$ to $\mathrm{H}_{2} \mathrm{O}_{2}$ and $\mathrm{O}_{2}$. Two hours after treatment with GTN (Fig. 1), the CuZnSOD activity in erythrocytes did not change significantly. In reticulocytes, two main isoforms of SOD exist: cytosolic $\mathrm{CuZnSOD}$ and mitochondrial MnSOD. Our results showed that GTN induced significant increase of CuZnSOD activity, while significantly and dose-dependently decreased MnSOD activity (Fig. 1, Tab. 3). Total SOD activity remained stable during the GTN treatment.

The activity of catalase, the next antioxidative enzyme which transforms $\mathrm{H}_{2} \mathrm{O}_{2}$ to $\mathrm{H}_{2} \mathrm{O}$ and $\mathrm{O}_{2}$, was also followed in RBCs in the presence of GTN. The obtained results showed that GTN did not change catalase activity in erythrocytes and reticulocytes (data not shown).

Three glutathione-dependent enzymes are also included in AOS as following: GSH-Px decomposes $\mathrm{H}_{2} \mathrm{O}_{2}$, GR reduces

Table 1. Effects of glyceryl trinitrate (GTN) on vitamin C (Vit C) and vitamin E (Vit E) concentrations in rat erythrocytes and reticulocytes

\begin{tabular}{|c|c|c|c|c|}
\hline \multirow{2}{*}{$\begin{array}{l}\text { GTN } \\
(\mathrm{mM})\end{array}$} & \multicolumn{2}{|c|}{ Vit C ( $\mu \mathrm{mol} / \mathrm{ml}$ cells $)$} & \multicolumn{2}{|c|}{ Vit E ( $\mu \mathrm{g} / \mathrm{ml}$ cells) } \\
\hline & Erythrocytes & Reticulocytes & Erythrocytes & Reticulocytes \\
\hline 0 & $166.74 \pm 23.97$ & $89.93 \pm 16.15$ & $5.10 \pm 1.89$ & $3.00 \pm 0.53$ \\
\hline 0.1 & $164.05 \pm 22.88$ & $72.64 \pm 14.84$ & $6.03 \pm 1.21$ & $3.04 \pm 0.28$ \\
\hline 0.25 & $117.34 \pm 11.08^{*}$ & $74.45 \pm 13.36$ & $7.80 \pm 1.75$ & $2.66 \pm 0.55$ \\
\hline 0.5 & $147.77 \pm 24.98$ & $59.28 \pm 13.85^{\star}$ & $5.55 \pm 1.65$ & $3.55 \pm 0.35$ \\
\hline 1.0 & $122.47 \pm 23.23$ & $70.30 \pm 17.76$ & $11.07 \pm 1.09^{*}$ & $4.54 \pm 0.28^{*}$ \\
\hline 1.5 & $122.47 \pm 36.37$ & $57.70 \pm 3.47^{\star}$ & $10.32 \pm 2.61^{\star}$ & $4.93 \pm 0.47^{\star}$ \\
\hline
\end{tabular}

Values represent mean \pm SEM for 5 experiments. ${ }^{\star} p<0.05$, control (0 mM GTN) versus GTN (other concentrations).

Table 2. Effects of GTN on concentrations of reduced (GSH) and oxidized (GSSG) form of glutathione in rat erythrocytes and reticulocytes

\begin{tabular}{|c|c|c|c|c|c|c|}
\hline \multirow{2}{*}{$\begin{array}{l}\text { GTN } \\
(\mathrm{mM})\end{array}$} & \multicolumn{2}{|c|}{$\mathrm{GSH}(\mu \mathrm{mol} / \mathrm{ml}$ cells $)$} & \multicolumn{2}{|c|}{ GSSG (nmol/ml cells) } & \multicolumn{2}{|c|}{$\mathrm{GSSG} / 2 \mathrm{GSH} \times 10^{-3}$} \\
\hline & Erythrocytes & Reticulocytes & Erythrocytes & Reticulocytes & Erythrocytes & Reticulocytes \\
\hline 0 & $2.22 \pm 0.20$ & $3.51 \pm 0.32$ & $0.58 \pm 0.10$ & $0.62 \pm 0.09$ & 0.13 & 0.09 \\
\hline 0.1 & $2.06 \pm 0.16$ & $3.30 \pm 0.34^{*}$ & $0.58 \pm 0.07$ & $0.73 \pm 0.11$ & 0.14 & 0.11 \\
\hline 0.25 & $1.92 \pm 0.13$ & $3.50 \pm 0.39$ & $0.54 \pm 0.11$ & $0.70 \pm 0.08$ & 0.14 & 0.10 \\
\hline 0.5 & $2.10 \pm 0.20$ & $3.16 \pm 0.34^{*}$ & $0.54 \pm 0.13$ & $0.70 \pm 0.16$ & 0.13 & 0.11 \\
\hline 1.0 & $1.78 \pm 0.28^{\star}$ & $2.96 \pm 0.29^{*}$ & $0.47 \pm 0.11$ & $0.72 \pm 0.07$ & 0.13 & 0.12 \\
\hline 1.5 & $1.25 \pm 0.26^{*}$ & $2.83 \pm 0.25^{*}$ & $0.30 \pm 0.05^{*}$ & $0.65 \pm 0.08$ & 0.12 & 0.115 \\
\hline
\end{tabular}

Values represent mean \pm SEM for 5 experiments. ${ }^{\star} p<0.05$, control ( $\left.0 \mathrm{mM} \mathrm{GTN}\right)$ versus GTN (other concentrations). 
ERYTHROCYTES

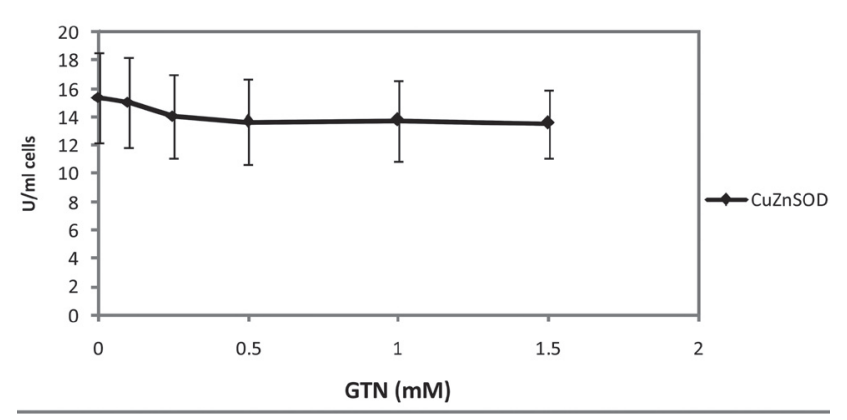

RETICULOCYTES

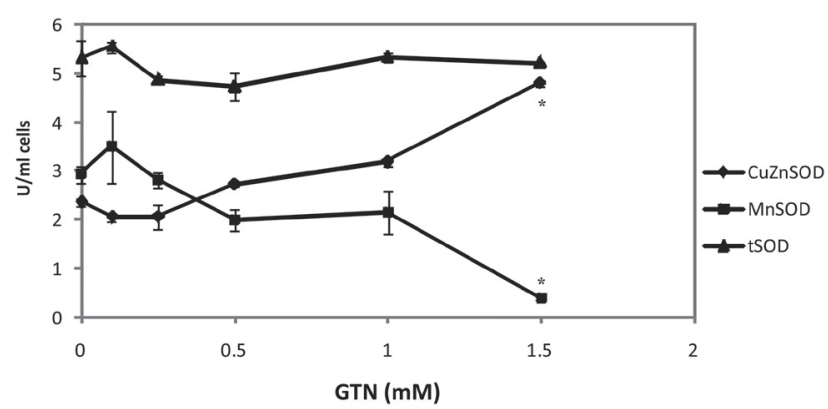

Figure 1. Effects of glyceryl trinitrate (GTN) on CuZn superoxide dismutase (CuZnSOD), MnSOD and total SOD (tSOD) activities in rat erythrocytes and reticulocytes. Values represent mean \pm SEM for 5 experiments. Values for SOD are in $\mathrm{U} / \mathrm{ml}$ cells $\times 10^{4} .{ }^{*} p<0.05$, control (0 mM GTN) versus GTN (other concentrations).

oxidized form of glutathione to GSH, GST catalyses GSH conjugation with diverse xenobiotics, inactivating or metabolizing them. The basal (control, untreated RBCs) activities of all glutathione-dependent enzymes were significantly lower in reticulocytes compared with erythrocytes (Fig. 2). The incubation of rat erythrocytes and reticulocytes in the presence of GTN resulted in significant decrease of GSH-Px, GR and GST activities in both cells (Fig. 2), mostly dosedependently (negative correlation with GTN concentration, Tab. 3). Also, there are evident increases of GSH-Px activity in erythrocytes and GR activities in both erythrocytes and reticulocytes in the presence of low doses of GTN (Fig. 2), indicating initially antioxidative capacity of these enzymes to protect RBCs from oxidative damage.

\section{The effects of GTN on OPP pathway activity}

Finally, we followed the activity of OPP pathway which supplied RBCs with reduced nicotinamide adenine dinucleotide phosphate (NADPH), a cofactor in antioxidative metabolism and glutathione metabolic pathway. The obtained results showed that GTN significantly increased glucose utilization through OPP pathway in both treated cells (Fig. 3),
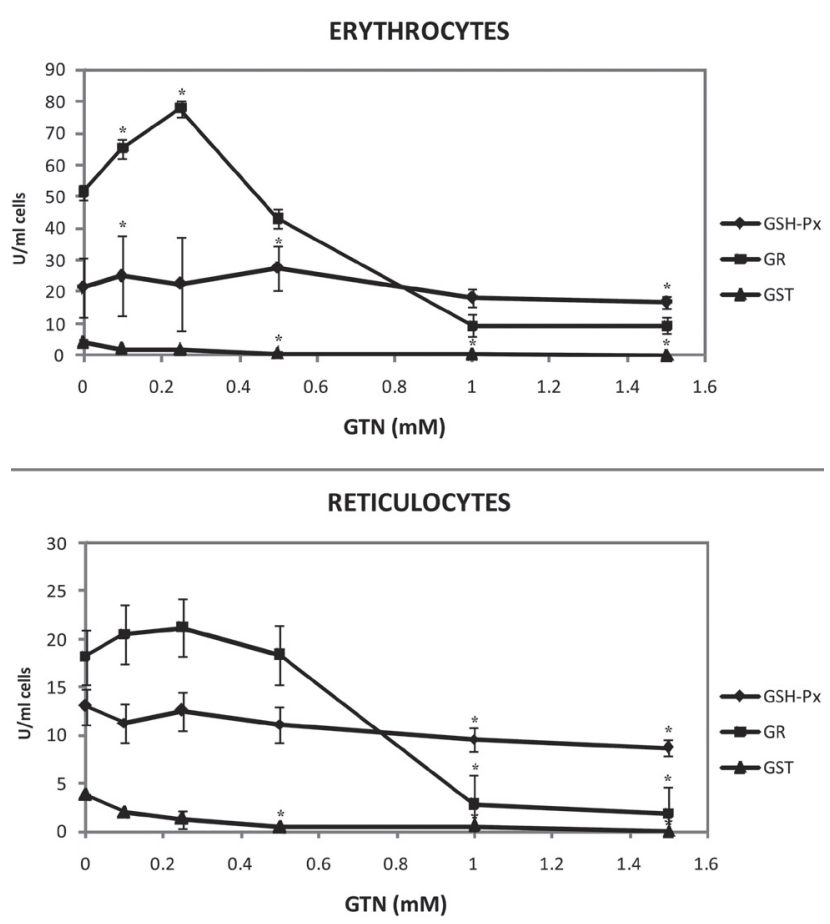

Figure 2. Effects of glyceryl trinitrate (GTN) on glutathione peroxidase (GSH-Px), glutathione reductase (GR) and glutathione S-transferase (GST) activities in rat erythrocytes and reticulocytes. Values represent mean \pm SEM for 5 experiments. Values for GSH-Px and GST are in $\mathrm{U} / \mathrm{ml}$ cells $\times 10^{3}$ and for GR in $\mathrm{U} / \mathrm{ml}$ cells $\times 10^{5} .{ }^{*} p<0.05$, control (0 mM GTN) versus GTN (other concentrations).

Table 3. Linear correlation between concentrations of GTN and effects on followed parameters

\begin{tabular}{lcc}
\hline & \multicolumn{2}{c}{ Correlation with GTN doses $(\mathrm{r})$} \\
\cline { 2 - 3 } & Erythrocytes & Reticulocytes \\
\hline Vit C & -0.672 & -0.717 \\
Vit E & $0.844^{*}$ & $0.953^{* *}$ \\
GSH & $-0.923^{\star *}$ & $-0.936^{* *}$ \\
GSSG & $-0.953^{\star *}$ & 0.227 \\
CuZnSOD & -0.785 & $0.945^{* *}$ \\
MnSOD & - & $-0.922^{* *}$ \\
tSOD & - & -0.028 \\
CAT & $0.884^{*}$ & -0.791 \\
GSH-Px & -0.688 & $-0.928^{* *}$ \\
GR & $-0.871^{\star}$ & $-0.922^{* *}$ \\
GST & $-0.829^{*}$ & 0.793 \\
OPP & $0.999^{* *}$ & $0.993^{* *}$ \\
\hline
\end{tabular}

GTN, glyceryl trinitrate; Vit C, vitamin C; Vit E, vitamin E; GSH, reduced glutathione; GSSG, oxidized glutathione; $\mathrm{SOD}$, superoxide dismutase; tSOD, total SOD; CAT, catalase; GSH-Px, glutathione peroxidase; GR, glutathione reductase; GST, glutathione S-transferase; OPP, oxidative pentose phosphate; $r$, coefficient of correlation; ${ }^{*}$ correlation is significant at the 0.05 level ( 2 tailed) and ${ }^{* *}$ at the 0.01 level ( 2 tailed). 
suggesting the increase of reduced capacity for antioxidative defense of RBCs.

\section{Discussion}

The mitochondria had a significant role in the enzymatic biotransformation of GTN (Chen et al. 2002; Sydow et al. 2004; Daiber et al. 2009). Previously, we showed that GTN induced inhibition of energy production through oxidative phosphorylation and stimulation of uncoupled oxygen consumption in rat reticulocytes (Maletić and Kostić 1999). The increase of uncoupled oxygen consumption is the result of elevated RNS (peroxynitrite) and ROS (hydrogen peroxide) levels and the oxidative stress in these cells (Marković et al. 2006). GTN increased glucose utilization through glycolysis pathway (Maletić and Kostić 1999; Maletić et al. 2000) and through OPP pathway in rat erythrocytes and reticulocytes (results of this study), which indicates the elevation of reductive capacities (NADH and $\mathrm{NADPH}$, respectively) as a primary cell response to the induced oxidative stress. However, these elevations in reduced capacity of RBCs were not enough to prevent GTN-induced general depletion of glutathione-dependent antioxidative pool (results of this study) and consequent oxidative damage of cells (Marković

\section{ERYTHROCYTES}

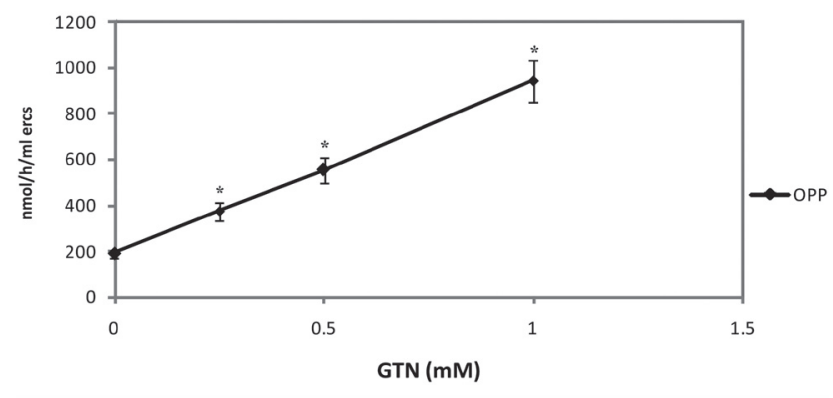

RETICULOCYTES

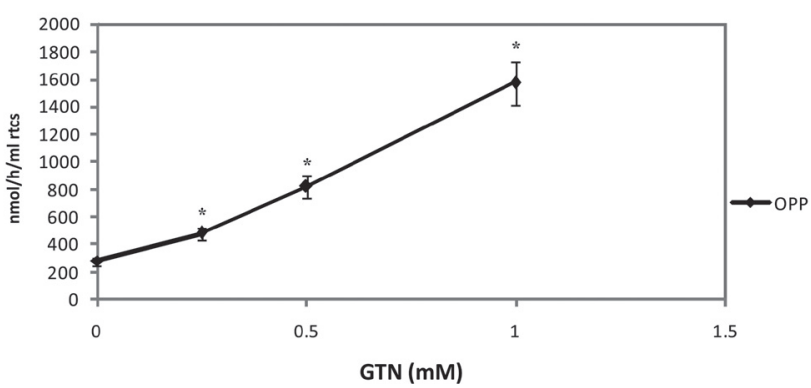

Figure 3. Effects of glyceryl trinitrate (GTN) on oxidative pentose phosphate (OPP) pathway activities in rat erythrocytes and reticulocytes. Values represent mean \pm SEM for 4 experiments. ${ }^{*} p<0.05$, control (0 mM GTN) versus GTN (other concentrations). et al. 2006). Literature data suggest that biotransformation of organic nitrates should proceed via two steps, where $\mathrm{NO}_{2}{ }^{-}$is an intermediate and precursor of $\mathrm{NO}$ (Chen et al. 2002). Nitrite reductase activity has been linked, except the others metabolic/enzymatic pathways, to the mitochondrial electron transport system (Kozlov et al. 1999) and deoxyhemoglobin (Cosby et al. 2003; Huang et al. 2005). The primary role for ALDH-2 in mediating the biotransformation of organic nitrates to $\mathrm{NO}$, resulting in increased cGMP accumulation and vasodilatation was established (Chen et al. 2002; Sydow et al. 2004). Moreover, recombinant ALDH 3A1 showed in vitro organic nitrate bioactivation (Lin et al. 2013). On the other side, in vivo studies suggest that GTN induced vasorelaxation through soluble guanylat cyclase (sGC)/cGMP pathway without intermediacy of NO (Kleschyov et al. 2003). Also, recent study suggests that in an intact cell system (porcine renal epithelial cells with intact NO-sGC-cGMP signalling system), neither overexpression nor depletion of ALDH-2 affects GTN-induced cGMP formation, indicating that ALDH-2 does not mediate biotransformation of GTN to an activator of sGC (D'Souza et al. 2013). Seabra et al. (2013) suggest that glyceraldehyde3-phosphate dehydrogenase catalyses nitrite generation from GTN. So, there are evidences that biotransformation of GTN is not simple and mediated by different enzymatic and nonenzymatic pathways in cells.

Literature data showed that mitochondrial $\mathrm{O}_{2}{ }^{\cdot-}$, causing reduced bioactivation of $\mathrm{NO}$, has a central role in the nitrate tolerance that develops during GTN treatment (Münzel et al. 1995; Sydow et al. 2004; Daiber et al. 2009). Mitochondrial MnSOD dismutate $\mathrm{O}_{2}{ }^{--}$to $\mathrm{H}_{2} \mathrm{O}_{2}$, thereby preventing peroxynitrite $\left(\mathrm{ONOO}^{-}\right)$formation. Daiber et al. (2005) noted more pronounced nitrate tolerance in a mouse model of heterozygous deletion of MnSOD. Our results showed that NTG decreased MnSOD activity in reticulocytes, probably as a consequence of peroxynitrite induced inhibition (Filipović et al. 2007). It is widely assumed that the major source of $\mathrm{ONOO}^{-}$in vivo is the extremely rapid reaction of $\mathrm{NO}$ with $\mathrm{O}_{2}{ }^{\bullet-} \cdot\left(\cdot \mathrm{NO}+\mathrm{O}_{2}{ }^{\cdot-} \rightarrow \mathrm{ONOO}^{-}\right)$. Peroxynitrite is a strong oxidant and nitration agens and number of studies have pointed to MnSOD as a predominant nitrated protein and MnSOD is inhibited under those conditions (Filipović et al. 2007). Previous results show that MnSOD-catalyzed NO dismutation into nitrosonium and nitroxyl species under anaerobic conditions (Niketić et al. 1999) is also operative in the presence of molecular oxygen which in reaction with nitrosonium gives peroxynitrite (Filipović et al. 2007). Reduction of RNS by GSH can suppress inhibition of MnSOD (Filipović et al. 2007). We showed that GTN caused an increase in the concentration of nitrites and peroxynitrite, leading to the development of oxidative damage in reticulocytes (Marković et al. 2006), and significant decrease of GSH concentration (results of this study). All these data 
suggest possibly a novel, important role of MnSOD in GTN biotransformation.

Our results also showed that GTN increased CuZnSOD activity in reticulocytes, which followed by lower $\mathrm{O}_{2}{ }^{--}$and higher $\mathrm{H}_{2} \mathrm{O}_{2}$ concentration of (Marković et al. 2006). Transformation of GTN in reticulocytes leads to increased NO production. Extremely rapid reaction of NO with $\mathrm{O}_{2}{ }^{--}$produce $\mathrm{ONOO}^{-}$, which induce inhibition of MnSOD. Measured increased CuZnSOD activity at high GTN dose may consequence of compensatory reaction in the cytosol of reticulocytes. According to given results, CuZnSOD successfully compensates MnSOD contribution in redox metabolism.

In erythrocytes without mitochondria, reduced $\mathrm{Hb}$ and low molecular weight thiols have a significant role in GTN biotransformation (Bennet et al. 1985; Boesgaard 1995). The study of Boesgaard (1995) suggested that in vivo intracellular GSH played a critical role in the metabolism of GTN and that intracellular depletion of GSH was involved in the conversion of $\mathrm{NO}_{2}{ }^{-}$to $\mathrm{NO}$. Our previous results showed that biotransformation of GTN in erythrocytes were primarily connected with $\mathrm{Hb}$ and increased MetHb level (Marković et al. 2006). Nitrites, which are released after the biotransformation of GTN, react with deoxyHb to form NO and MetHb in the erythrocytes (Cosby et al. 2003; Dejam et al. 2005). The proposed mechanisms is that released NO can react with GSH to form S-nitrosoglutathione (GSNO), which can react with GSH and produce $\mathrm{NO}^{-}$and GSSG (Hogg 2002). Decreased concentration of GSH (results of this study) suggests that the biotransformation of GTN may occur through the formation of GSNO. GSSG, which is generated in this reaction, can be reduced to GSH enzymatically by GR, or can be excreted from the erythrocytes (Huang and Huang 2002). According to our results, GR activity provides the conversion of GSSG to GSH at low doses of GTN. At higher doses of GTN, GR activity decreases and GSH/GSSG ratio is maintained probably through excretion of GSSG from cells. The obtained results suggest that $\mathrm{Hb}$ and GSH dependent metabolism of GTN exist in reticulocytes as well.

Our results showed that the basal (control, untreated RBCs) activities of all glutathione-dependent enzymes were significantly lower in reticulocytes compared with erythrocytes, indicating immature state of glutathione metabolic pathway in reticulocytes (Rapoport 1986). Another explanation for these data is that $\mathrm{PhCl}$-induced reticulocytosis is followed by up-regulated oxidative stress in reticulocytes (Marković et al. 2006) and consequently ROS/RNS-induced inhibition of glutathione-dependent enzymes (Becker et al. 1998). GTN treatment at low doses increases GSH-Px and GR activities (except for GSH-Px in reticulocytes) and in higher doses it decreases the activities of all investigated glutathione-dependent enzymes in rat RBCs. The increased activity of GSH-Px at low GTN doses protects RBCs from oxidative damage. Reduction of GSH-Px activity and induction of oxidative damage of RBCs are the consequence of GSH loss, caused by high doses of GTN. Kinetic studies show that GSNO is a competitive inhibitor of GST and GR, and it has been proposed as activity modulator of these enzymes (Becker et al. 1995; Keese et al. 1997). In addition, direct inactivation of glutathione-dependent enzymes in the reaction of RNS with SH-groups of their active centers (Becker et al. 1998) may be the cause of GTN-induced inhibition of these enzymes in rat RBCs. Also, the peroxynitrite, which increases under the influence of GTN in reticulocytes (Marković et al. 2006) can nitrate tyrosine residues of GST, which leads to inhibition of activity (Wong et al. 2001).

The results of our study showed that GTN had tendency to decrease of Vit C level (more details in Results), while at high doses it increased Vit E level in both erythrocytes and reticulocytes. Studies showed that oxidative stress and depletion of Vit $\mathrm{C}$ had an important role in development of nitrate tolerance during GTN treatment (Kollau et al. 2007; Wölkart et al. 2008). Also, Vit C plays an important role in maintaining the level of Vit E (Beyer 1994). Acting as a chain breaking antioxidant, Vit E can stop the chain reaction of lipid peroxidation and contribute to maintain the stability of the cell membrane (Beyer 1994). Considering that GTN at high doses induced lipid peroxidation (Marković et al. 2006), the increased concentration of Vit $\mathrm{E}$ had a protective effect on the RBCs membrane. The data obtained in this study indicate that water soluble Vit C and GSH were engaged in antioxidative defense of RBCs after GTN induction of oxidative stress. As a consequence, the pool of fat soluble Vit E was preserved. In our experimental design, $\mathrm{PhCl}$-induced reticulocytosis was followed by up-regulated oxidative stress and reticulocytes were adapted to oxidative stress in contrast to the erythrocytes (Marković et al. 2006).

In conclusion, according to our results, RBCs have a significant role in the biotransformation of GTN and preservation of NO bioactivity. Hemoglobin and GSH play critical roles in the biotransformation of GTN in rat erythrocytes and partly in reticulocytes where MnSOD probably had the main role. We suggest that oxidative stress, MnSOD inhibition and depletion of glutathione pool in response to GTN treatment lead to decreased bioavailability of NO after GTN biotransformation in rat reticulocytes. This study is significant in definition the reticulocytes as an experimental model system for investigation of mitochondria-dependent metabolic pathways.

Acknowledgements. This work was supported by the Serbian Ministry of Education, Science and Technological Development, Grant No III41010 and OI173041. The authors thank to Prof. dr Radmila Stajn for proofreading of manuscript.

Conflict of interest: The authors have no conflicts. 


\section{References}

Becker K., Gui M., Schirmer R. H. (1995): Inhibition of human glutathione reductase by S-nitrosoglutathione. Eur. J. Biochem. 234, 472-478 http://dx.doi.org/10.1111/j.1432-1033.1995.472_b.x

Becker K., Savvides S. N., Keese M., Schrimer R. H., Karplus P. A. (1998): Enzyme inactivation through sulfhydryl oxidation by physiologic NO-carrers. Nat. Struct. Biol. 5, 267-271 http://dx.doi.org/10.1038/nsb0498-267

Bennett B. M., Brien J. F., Nakatsu K., Marks G. S. (1985): Role of hemoglobin in the differential biotransformation of glyceryl trinitrate and isosorbide dinitrate by human erythrocytes. J. Pharmacol. Exp. Ther. 234, 228-232

Beutler E. (1975a): Reduced glutathione (GSH). In: Red Cell Metabolism. A Mannual of Biochemical Methods. (Ed. E. Beutler), pp 112-114, Grune and Straton, New York

Beutler E. (1975b): Oxidized glutathione (GSSG). In: Red Cell Metabolism. A Mannual of Biochemical Methods. (Ed. E. Beutler), pp 115-117, Grune and Straton, New York

Beutler E. (1982): Catalase. In: Red Cell Metabolism. A Mannual of Biochemical Methods. (Ed. E. Beutler), pp 105-106, Grune and Straton, New York

Beyer R. E. (1994): The role of ascorbate in antioxidant protection of biomolecules: interaction with vitamin $\mathrm{E}$ and coenzyme $\mathrm{Q}$ J. Bioenerg. Biomemb. 26, 349-358 http://dx.doi.org/10.1007/BF00762775

Boesgaard S. (1995): Thiol compounds and organic nitrates. Dan. Med. Bull. 42, 473-484

Chen Z., Zhang J., Stamler J. S. (2002): Identification of the enzymatic mechanism of nitroglycerin bioactivation. Proc. Natl. Acad. Sci. U.S.A. 99, 8306-8311 http://dx.doi.org/10.1073/pnas.122225199

Cosby K., Partovi K. S., Crawford J. H., Patel R. P., Reiter C. D., Martyr S., Yang B. K., Waclawiw M. A., Zalos G., Xu X., et al. (2003): Nitrite reduction to nitric oxide by deoxyhemoglobin vasodilates the human circulation. Nat. Med. 9, 1498-1505 http://dx.doi.org/10.1038/nm954

Daiber A., Oelze M., Sulyok S., Coldewey M., Schulz E., Treiber N., Hink U., Mülsch A., Scharffetter-Kochanek K., Münzel T. (2005): Heterozygous deficiency of manganese superoxide dismutase in mice (Mn-SOD+/-): a novel approach to assess the role of oxidative stress for the development of nitrate tolerance. Mol. Pharmacol. 68, 579-588

Daiber A., Oelze M., Wenzel P., Wickramanayake J. M., Schuhmacher S., Jansen T., Lackner K. J., Torzewski M., Münzel T. (2009): Nitrate tolerance as a model of vascular dysfunction: Roles for mitochondrial aldehyde dehydrogenase and mitochondrial oxidative stress. Pharmacol. Rep. 61, 33-48 http://dx.doi.org/10.1016/S1734-1140(09)70005-2

Day B. R., Williams D. R., Marsh C. A. (1979): A rapid manual method for routine assay of ascorbic acid in serum and plasma. Clin. Biochem. 12, 22-26 http://dx.doi.org/10.1016/S0009-9120(79)90040-7

Dejam A., Hunter C. J., Pelletier M. M., Hsu L. L., Machado R. F., Shiva S., Power G. G., Kelm M., Gladwin M. T., Schechter A. N. (2005): Erythrocytes are the major intravascular storage sites of nitrite in human blood. Blood 106, 734-739 http://dx.doi.org/10.1182/blood-2005-02-0567

Desai I. D. (1984): Vitamin E analysis methods for animal tissues. Methods. Enzymol. 105, 138-147

http://dx.doi.org/10.1016/S0076-6879(84)05019-9

Dröge W. (2002): Free radicals in the physiological control of cell function. Physiol. Rev. 82, 47-95

D’Souza Y., Ji Y., Bennett B. M. (2013): Effect of overexpression of human aldehyde dehydrogenase 2 in LLC-PK1 cells on glyceryl trinitrate biotransformation and cGMP accumulation. Br. J. Pharmacol. 168, 978-987 http://dx.doi.org/10.1111/j.1476-5381.2012.02220.x

Filipović M. R., Stanić D., Raicević S., Spasić M., Niketić V. (2007): Consequences of MnSOD interactions with nitric oxide: nitric oxide dismutation and the generation of peroxynitrite and hydrogen peroxide. Free Radic. Res. 41, 62-72 http://dx.doi.org/10.1080/10715760600944296

Glatzle D., Vuilleumier J. P., Weber F., Decker K. (1974): Glutathione reductase test with whole blood, a convinient procedure for the assessment of riboflavin status in humans. Experientia 30, 665-667 http://dx.doi.org/10.1007/BF01921531

Habig W. H., Pabst M. J., Jakobay W. B. (1974): Glutathione Stransferase. J. Biol. Chem. 249, 7130-7139

Hogg N. (2002): The biochemistry and physiology of S-nitrosothiols. Annu. Rev. Pharmacol. Toxicol. 42, 585-600 http://dx.doi.org/10.1146/annurev.pharmtox.42.092501.104328

Huang K. P., Huang F. L. (2002): Glutathionylation of proteins by glutathione disulfide S-oxide. Biochem. Pharmacol. 64, 1049-1056 http://dx.doi.org/10.1016/S0006-2952(02)01175-9

Huang Z., Shiva S., Kim-Shapiro D. B., Patel R. P., Ringwood L. A., Irby C. E., Huang K. T., Ho C., Hogg N., Schechter A. N., Gladwin M. T. (2005): Enzymatic function of haemoglobin as a nitrite reductase that produces $\mathrm{NO}$ under allosteric control. J. Clin. Invest. 115, 2099-2107 http://dx.doi.org/10.1172/JCI24650

Keese M. A., Böse M., Mülsch A., Schirmer R. H., Becker K. (1997): Dinitrosyl-dithiol-iron complexes, nitric oxide (NO) carriers in vivo, as potent inhibitors of human glutathione reductase and glutathione-S-transferase. Biochem. Pharmacol. 54, 1307-1313 http://dx.doi.org/10.1016/S0006-2952(97)00348-1

Kleschyov A. L., Oelze M., Daiber A., Huang Y., Mollnau H., Schulz E., Sydow K., Fichtlscherer B., Mülsch A., Münzel T. (2003): Does nitric oxide mediate the vasodilator activity of nitroglycerin? Circ. Res. 93, 104-112 http://dx.doi.org/10.1161/01.RES.0000100067.62876.50

Kollau A., Beretta M., Gorren A. C., Russwurm M., Koesling D., Schmidt K., Mayer B. (2007): Bioactivation of nitroglycerin by ascorbate. Mol. Pharmacol. 72, 191-196 http://dx.doi.org/10.1124/mol.107.035642

Kostić M. M., Živković R. V., Rapoport S. M. (1990) : Maturationdependent changes of the rat reticulocyte energy metabolism and hormonal responsiveness. Biomed. Biochim. Acta 49, $178-182$

Kozlov A. V., Staniek K., Nohl H. (1999): Nitrite reductase activity is a novel function of mammalian mitochondria. FEBS Lett. 454, 127-130 http://dx.doi.org/10.1016/S0014-5793(99)00788-7 
Kuka S., Tatarkova Z., Racay P., Lehotsky J., Dobrota D., Kaplan P. (2013): Effect of ageing on formation of reactive oxygen species by mitochondria of rat heart. Gen. Physiol. Biophys. 32, 415-420 http://dx.doi.org/10.4149/gpb_2013049

Lin S., Page N. A., Fung S. M., Fung H. L. (2013): In vitro organic nitrate bioactivation to nitric oxide by recombinant aldehyde dehydrogenase 3A1. Nitric Oxide 35, 137-143 http://dx.doi.org/10.1016/j.niox.2013.09.005

Maletić S. D., Kostić M. M. (1999): Effects of nitroglycerin on energy metabolism of rat reticulocytes. J. Physiol. Pharmacol. 50, 75-87

Maletić S. D., Dragićević-Djoković Lj. M., Žikić R. V., Štajn A. Š., Milenković P., Kostić M. M. (2000): Effects of nitric oxide donors on energy metabolism of rat erythrocytes. J. Environ. Pathol. Toxicol. Oncol. 19, 383-390

Maral J., Puget K., Michelson A. M. (1977): Comparative study of superoxide dismutase, catalase and glutathione peroxidase levels in erythrocytes of different animals. BBRC 77, 1525-1535

Marklund S., Marklund G. (1974): Involvement of superoxide anion radical in the autoxidation of pyrogallol and a constituent assay for superoxide dismutase. Eur. J. Biochem. 47, 469-479 http://dx.doi.org/10.1111/j.1432-1033.1974.tb03714.x

Marković S. D., Ognjanović B. I., Štajn A. Š., Žikić R. V., Saičić Z. S., Radojičić R. M., Spasić M. B. (2006): The effects of nitroglycerine on the redox status of rat erythrocytes and reticulocytes. Physiol. Res. 55, 389-396

Marković S. D., Vukajlović M. Dj., Ognjanović B. I., Štajn A. Š., Žikić R. V., Saičić Z. S., Radojičić R. M., Jones D. R., Spasić M. B. (2007): A comparative study of the effects of molsidomine and 3-morpholinosydnonimine on redox status of rat erythrocytes and reticulocytes. Cell Biochem. Funct. 25, 251-258 http://dx.doi.org/10.1002/cbf.1320

Marković S. D., Žižić J. B., Obradović A. D., Ognjanović B. I., Štajn A. Š., Saičić Z. S., Spasić M. B. (2011): Energy production and redox status of rat red blood cells after reticulocytosis induced by various treatments. Acta Biol. Hung. 62, 122-132 http://dx.doi.org/10.1556/ABiol.62.2011.2.2

Münzel T., Sayegh H., Freeman B. A., Tarpey M. M., Harrison D. G. (1995): Evidence for enhanced vascular superoxide anion production in nitrate tolerance. A novel mechanism underlying tolerance and cross-tolerance. J. Clin. Invest. 95, 187-194
http://dx.doi.org/10.1172/JCI117637

Niketić V., Stojanović S., Nikolić A., Spasić M., Michelson A. M. (1999): Exposure of Mn and FeSOD, but not Cu/ZnSOD, to NO lids to nitrosonium and nitroxyl ions generation which cause enzyme modification and inactivation: an in vitro study. Free Radic. Biol. Med. 27, 992-996 http://dx.doi.org/10.1016/S0891-5849(98)00256-1

Nikolić-Kokić A., Blagojević D., Spasić M. (2010): Complexity of free radical metabolism in human erythrocytes. J. Med. Biochem. 29, 189-195 http://dx.doi.org/10.2478/v10011-010-0018-7

Rapoport S. M. (1986): The Reticulocyte. CRC Press Inc., Bocca Raton, Florida

Seabra A. B., Ouellet M., Antonic M., Chrétien M. N., English A. M. (2013): Catalysis of nitrite generation from nitroglycerin by glyceraldehyde-3-phosphate dehydrogenase (GAPDH). Nitric Oxide 35, C, 116-122 http://dx.doi.org/10.1016/j.niox.2013.09.003

Sydow K., Daiber A., Oelze M, Chen Z., August M., Wendt M., Ullrich V., Mulsch A., Schulz E., Keaney J. F. Jr, Stamler J. S., Munzel T. (2004): Central role of mitochondrial aldehyde dehydrogenase and reactive oxygen species in nitroglycerin tolerance and cross-tolerance. J. Clin. Invest. 113, 482-489 http://dx.doi.org/10.1172/JCI200419267

Umbreit J. (2007): Methemoglobin-it's not just blue: a concise review. Am. J. Hematol. 82, 134-144 http://dx.doi.org/10.1002/ajh.20738

Wölkart G., Wenzl M. V., Beretta M., Stessel H., Schmidt K., Mayer B. (2008): Vascular tolerance to nitroglycerin in ascorbate deficiency. Cardiovasc. Res. 79, 304-312 http://dx.doi.org/10.1093/cvr/cvn107

Wong P. S., Eiserich J. P., Reddy S., Lopez C. L., Cross C. E., van der Vilet A. (2001): Inactivation of glutathione S-transferases by nitric oxide-derived oxidants: exploring a role for tyrosine nitration. Arch. Biochem. Biophys. 394, 216-228 http://dx.doi.org/10.1006/abbi.2001.2532

Yunis J. J., Yashmineh W. G. (1969): Glucose metabolism in human erythrocytes. In: Biochemical Methods in Red Cell Genetics. (Ed. J. J. Yunis), pp 1-49, Academic Press, New York

Received: March 14, 2014

Final version accepted: May 26, 2014

First published online: August 22, 2014 